\title{
Role of leptin and the leptin receptor in the pathogenesis of varicocele-induced testicular dysfunction
}

\author{
JIE ZHANG ${ }^{1}$, PENG-PENG JIN ${ }^{2}$, MIN GONG ${ }^{1}$, QING-TONG YI ${ }^{1}$ and RU-JIAN ZHU ${ }^{1}$ \\ ${ }^{1}$ Department of Urology and ${ }^{2}$ Center for Medical Research, Shanghai Pudong Hospital, \\ Fudan University, Shanghai 201399, P.R. China
}

Received December 5, 2017; Accepted March 1, 2018

DOI: $10.3892 / \mathrm{mmr} .2018 .8753$

\begin{abstract}
The present study investigated the expression of leptin and its receptor in the left testis and hypothalamus of rats with varicocele and clarified their roles in the pathogenesis of varicocele-induced testicular dysfunction. A total of 40 male rats were divided randomly into four groups. Groups 1 (G1) and 3 (G3) underwent a sham operation. Groups 2 (G2) and 4 (G4) underwent operations to form a varicocele created by partial ligation of the left renal vein. G1 and G2 rats were euthanized 4 weeks after the operation while G3 and G4 rats were euthanized at 8 weeks. The expression of leptin and its receptor was analyzed by immunohistochemistry. The mRNA levels of leptin, its receptor, kisspeptin (KiSS-1), G-protein coupled receptor 54 (GPR54), gonadotropin releasing hormone (GnRH), luteinizing hormone ( $\mathrm{LH})$, and follicle-stimulating hormone (FSH) were measured by reverse transcription-quantitative polymerase chain reaction. Testicular spermatogenesis function and gonadal hormone levels were measured. Compared with G1 and G3, the expression of leptin and its receptor in rat testis was significantly higher in G2 and G4, respectively. Leptin expression was inversely associated with the number of sperm in the left epididymis, thickness of the seminiferous epithelium and the diameter of seminiferous tubules. The expression of leptin receptors in the hypothalamus of G2 and G4 was significantly increased compared with that in G1 and G3, respectively. The mRNA levels of KiSS-1, GPR54, GnRH, LH and FSH in G2 and G4 were significantly increased compared with that in G1 and G3, respectively. Serum testosterone levels in G2 and G4 rats were significantly lower than those in G1 and G3 rats, respectively. There was no significant difference between the serum levels of FSH, LH and leptin. These results suggest that leptin and its receptor may serve significant roles in the pathogenesis of varicocele-induced testicular dysfunction.
\end{abstract}

Correspondence to: Dr Min Gong, Department of Urology, Shanghai Pudong Hospital, Fudan University, 2800 Gongwei Road, Shanghai 201399, P.R. China

E-mail:mg813@hotmail.com

Key words: kisspeptin/G-protein coupled receptor 54 system, leptin, leptin receptor, testicular dysfunction, varicocele

\section{Introduction}

Varicocele is one of the most common causes of male infertility. In adult males, approximately $30-40 \%$ of patients with primary infertility, and $69-81 \%$ of patients with secondary infertility, suffer from varicocele (1). Varicocele is considered disadvantageous to spermatogenesis, leading to low sperm count, abnormal morphology, and poor motility. The academic community has put forward many hypotheses for varicocele-induced testicular dysfunction including oxidative stress, increased apoptosis, hypoxia, and testicular microcirculation abnormalities. However, the exact mechanism has not yet been fully elucidated (2).

Leptin, secreted mainly by white adipose tissue, is a protein product of an obese gene. Leptin receptors belong to the class I cytokine receptor family and have at least six different subtypes. Leptin which reaches the central or peripheral tissue is free in the blood or binds to the leptin binding protein (3). Differential leptin receptor activation conveys different biological activities of leptin (4). Leptin is a metabolic signal that connects nutrition and other physiological functions (5). Leptin not only plays an important role in energy metabolism, but also participates in a series of important physiological activities such as angiogenesis, immune regulation, inflammatory reaction and bone formation (6). Previous studies have focused on the role of leptin in energy metabolism. Recently, an increasing number of studies have shown that leptin plays an important role in regulating reproductive function $(7,8)$. It has been reported that leptin and the leptin receptor exist in testicular tissue (9), suggesting that they might be related to spermatogenesis dysfunction caused by varicocele. In addition, Ishikawa has found that testicular dysfunction is associated with increased leptin and leptin receptor expression (10). The purpose of this study was to elucidate the relationship between spermatogenesis dysfunction and the expressions of leptin and its receptor in rats with experimental varicocele. Furthermore, we examined the roles of leptin and the leptin receptor in the pathogenesis of varicocele-induced testicular dysfunction.

\section{Materials and methods}

Preparation of animals and tissues. Forty Sprague-Dawley male rats were obtained from Shanghai SIPPR-BK Laboratory or Animal Co., Ltd. (Shanghai, China). Weights ranged from 
200 to $250 \mathrm{~g}$. Rats were divided into four groups randomly: Groups 1 (G1) and 3 (G3) underwent the sham operation as controls; groups 2 (G2) and 4 (G4) underwent operations to form an experimental left varicocele which was created by partially narrowing the left renal vein with reference to Turner's method (11). Briefly, with a 4-0 silk suture passing under the left renal vein, a $0.7 \mathrm{~mm}$ diameter needle was placed above the left renal vein proximal to the junction of the left internal spermatic vein. The left renal vein and the needle were ligated together. The needle was withdrawn after the knot was secured resulting in partial narrowing of the vein. We then carefully looked for and ligated branches between the left internal spermatic and left common iliac veins.

G1 and G3 rats underwent left renal vein isolation without ligation. The diameters of both the left and right internal spermatic veins were measured under a microscope with a micrometer before and 4 or 8 weeks after the operation. Varicocele modeling was considered successful when the diameter of the left internal spermatic vein was more than twice the right vein and there was no renal atrophy (Fig. 1).

G1 and G2 rats were killed 4 weeks after the operation while G3 and G4 rats were killed at 8 weeks. The left testis and epididymis were obtained and their weight was recorded. After washing with phosphate-buffered saline (PBS), the epididymis was placed into $\mathrm{PBS}$ at $37^{\circ} \mathrm{C}$ for $10 \mathrm{~min}$ for semen analysis. Some testis tissues stored in tubes were placed into liquid nitrogen for measuring mRNA levels with the real-time polymerase chain reaction (RT-PCR). Others were fixed in Bouin's solution for histochemical analysis. Blood was drawn from the abdominal aorta and the supernatant was collected after centrifugation at $3,500 \mathrm{x}$ g for $15 \mathrm{~min}$ at $4^{\circ} \mathrm{C}$. Blood samples were obtained to measure hormone levels. Finally, hypothalamus tissues were obtained and preserved in liquid nitrogen. The study was approved by the Ethics Committee of Shanghai Municipal Commission of Health and family Planning (SWJW005).

Spermatogenesis assessment. Paraffin sections made from fixed testis were stained with hematoxylin and eosin. Twenty fields were analyzed randomly under a microscope. Each section of seminiferous tubules was graded with a Johnsen's score from 1 to 10 as described previously (12) and an average score was calculated. In addition, the diameter of the seminiferous tubules, and the thickness of the seminiferous epithelium, were analyzed using Image-Pro Plus (Media Cybernetics, Inc., Rockville, MD, USA). The epididymis was cut into two sections and incubated at $37^{\circ} \mathrm{C}$ for $10 \mathrm{~min}$ in $2 \mathrm{ml}$ PBS to allow sperm to swim out freely. A blood cell counter was used for sperm counts.

Immunohistochemical staining. A streptavidin-peroxidase kit was used to perform immunohistochemical staining (Beijing Zhongshan Golden Bridge Biotechnology Co., Ltd., Beijing, China). Hypothalamus was used for frozen sections and testis was used for paraffin sections. Slides were incubated for $20 \mathrm{~min}$ at room temperature in 3\% hydrogen peroxide to block endogenous peroxidase activity. All slides were then incubated for $1 \mathrm{~h}$ in goat serum, followed by an overnight incubation at $4^{\circ} \mathrm{C}$ with primary antibodies against leptin (sc-842; Santa Cruz Biotechnology, Inc., Santa Cruz,

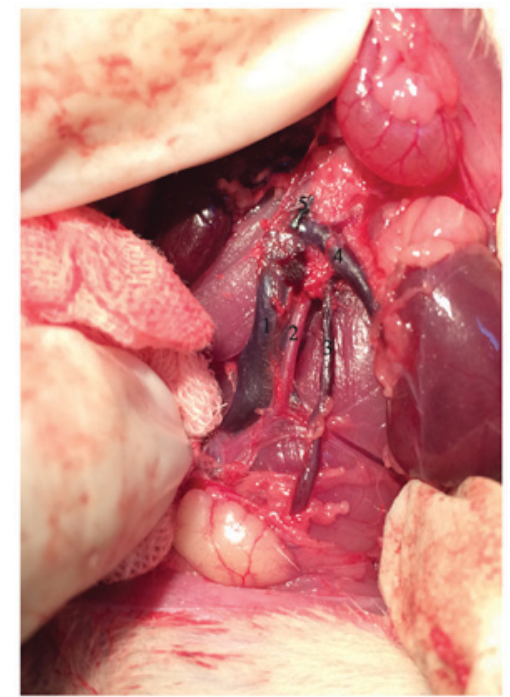

Figure 1. Development of the left varicocele. The experimental left varicocele was created by partially narrowing the left renal vein. 1 , inferior caval vein; 2, aortaventralis; 3, left internal spermatic vein; 4, left renal vein; 5, the knot.

CA, USA) or the leptin receptor (sc-8325; Santa Cruz Biotechnology, Inc.) at the dilution of 1:100. The following day, the slides were incubated with a biotinylated secondary antibody for $30 \mathrm{~min}$ at room temperature, and then with an enhanced streptavidin horseradish peroxidase conjugate for $15 \mathrm{~min}$ at room temperature. The slides were then washed and incubated with 3,3'-diaminobenzidine chromogenic reagent for $6 \mathrm{~min}$. Finally, all slides were counterstained with hematoxylin for $45 \mathrm{sec}$, destained with acid alcohol for $3 \mathrm{sec}$, dehydrated with an ethanol gradient, coated with resin, and covered with a glass coverslip. Image-Pro Plus was used to perform the quantitative analysis.

$R T$-PCR. Total RNA was extracted from cerebral and left testis tissues using TRIzol ${ }^{\circledR}$ Reagent (Ambion, Inc., Austin, TX, USA) according to the manufacturer's instructions. Total RNA $(1 \mu \mathrm{g})$ was reverse transcribed using QuantiTect Reverse Transcription kit (cat. nos. 205310, 205311, 205313, and 205314; Qiagen GmbH, Hilden, Germany). The primer sequences were synthesized by Sangon Biotech (Shanghai, China) (Table I). The RT-PCR reaction (ViiA ${ }^{\mathrm{TM}} 7$ Real-Time PCR; Applied Biosystems, Foster City, CA, USA) was started at $95^{\circ} \mathrm{C}$ for $10 \mathrm{~min}$, followed by 40 cycles at $95^{\circ} \mathrm{C}$ for $15 \mathrm{sec}$ and $60^{\circ} \mathrm{C}$ for $1 \mathrm{~min} . \beta$-actin was used to normalize the data and differences between the relative expression of the target genes were calculated according to the $2^{-\Delta \Delta C q}$ method. All reactions were performed in triplicate.

Hormone evaluations. Leptin was measured by an enzymelinked immunosorbent assay kit (Shanghai Westang Bio-Tech Co., Ltd., Shanghai, China). Follicle-stimulating hormone (FSH), luteinizing hormone (LH), and testosterone levels were determined by a radioimmunoassay (Beijing North Institute of Biological Technology, Beijing, China).

Statistical analysis. Data were analyzed using SPSS 20 (IBM Corp., Armonk, NY, USA). All values are shown as means \pm SEM. Statistical comparisons were performed using 
Table I. Primer sequences.

\begin{tabular}{|c|c|c|c|}
\hline Gene & Sequence $\left(5^{\prime}-3^{\prime}\right)$ & Product length (bp) & Accession number \\
\hline Leptin-F & CAATGACATTTCACACACGCAG & 204 & NM_013076 \\
\hline Leptin-R & AGATGGAGGAGGTCTCGCAG & & \\
\hline Leptin receptor-F & GTGTCCTTCCTGACTCCGTAG & 119 & NM_012596 \\
\hline Leptin receptor- $\mathrm{R}$ & GTTATTCTCTGGAAAGACTGGCT & & \\
\hline$\beta$-actin-F & GGCTGTATTCCCCTCCATCG & 154 & NM_007393 \\
\hline$\beta$-actin-R & CCAGTTGGTAACAATGCCATGT & & \\
\hline KiSS-1-F & TGGCACCTGTGGTGAACCCTGAAC & 202 & NM_181692 \\
\hline KiSS-1-R & ATCAGGCGACTGCGGCTGGCACAC & & \\
\hline GPR54-F & TTGGGTCCGAACGTGAGCT & 371 & NM_001301151 \\
\hline GPR54-R & CATGTGGCTTGCACCGAGA & & \\
\hline GnRH-F & CCGCTGTTGTTCTGTTGACT & 201 & NM_012767 \\
\hline GnRH-R & GCAGATCCCTAAGAGGTGAA & & \\
\hline LH-F & CССCATAGTCTCСТTТССТG & 190 & NM_012858 \\
\hline LH-R & GGATGGTTAGAACACCTGCT & & \\
\hline FSH-F & CATCCTACTCTGGTGCTTGA & 325 & NM_008045 \\
\hline FSH-R & TCTTACAGTGCAGTCGGTGC & & \\
\hline
\end{tabular}

F, forward; R, reverse; KiSS-1, kisspeptin; GPR54, G-protein coupled receptor 54; GnRH, gonadotropin releasing hormone; LH, luteinizing hormone; FSH, follicle-stimulating hormone; bp, base pairs.

Student's t-test and correlations were analyzed by using linear regression analysis. $\mathrm{P}<0.05$ was considered statistically different.

\section{Results}

Varicocele model and spermatogenesis assessment. One rat in the G2 group was excluded because of death and one in the G4 group was excluded because of unsuccessful modeling. Hematoxylin and eosin staining showed that the numbers of mature sperm in the seminiferous epithelium of G2 and G4 rats were significantly lower than those in G1 and G3 rats. Cells were relatively loose and disordered, and the number of vacuoles increased in G2 and G4 rats (Fig. 2).

There was no significant difference among groups in weights of the left testis and left epididymis. The Johnsen scores for the left testis of G2 and G4 rats were significantly lower, the seminiferous epithelium thinner, the seminiferous tubule diameters smaller, and the sperm counts lower than those in G1 and G3 rats, respectively (Table II).

Leptin and leptin receptor levels in testis and hypothalamus. Leptin and leptin receptors were expressed in the testis of all groups. Leptin was expressed in seminiferous tubules and intersitium while the leptin receptor was expressed predominantly in interstitium (Figs. 3 and 4). Expression of leptin and leptin receptors in the testis of G2 and G4 rats was increased significantly compared to G1 and G3 rats, respectively (Fig. 5). Leptin and leptin receptor mRNA levels in the testis of $\mathrm{G} 2$ and $\mathrm{G} 4$ rats were significantly increased compared to G1 and G3 rats, respectively (Fig. 6). Expression of leptin receptors in the hypothalamus of $\mathrm{G} 2$ and G4 rats was significantly increased compared to $\mathrm{G} 1$ and G3 rats, respectively (Fig. 7).
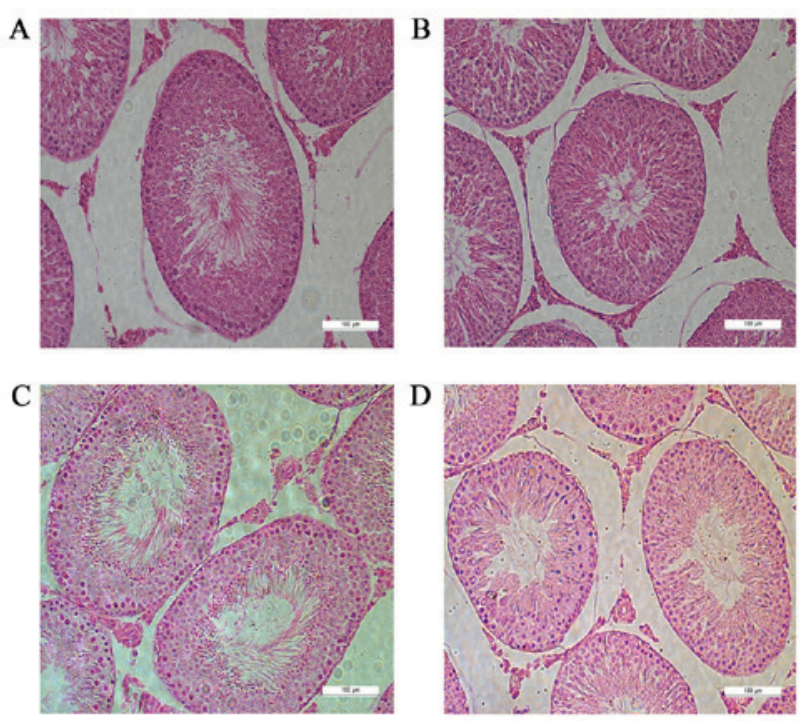

Figure 2. Hematoxylin and eosin staining in the (A) G1, (B) G2, (C) G3 and (D) G4 groups. Magnification, x200. G1 and G3 were the control groups and G2 and G4 were the experimental varicoceles groups. Cells were relatively loose and disordered and the number of vacuoles increased in the G2 and G4 rat groups. G1, group 1; G2, group 2; G3, group 3; G4, group 4.

Expression of kisspeptin (KiSS-1), G-protein coupled receptor 54 (GPR54), gonadotropin releasing hormone $(\mathrm{GnRH}), \mathrm{LH}$, and FSH mRNA in hypothalamus tissue. KiSS-1, GPR54, GnRH, LH, and FSH mRNA levels in G2 and G4 rats were significantly increased compared to G1 and G3 rats, respectively (Fig. 8).

Hormone levels. Serum testosterone levels in G2 and G4 rats were significantly lower than those in G1 and G3 rats, 
Table II. Spermatogenesis-associated indexes.

\begin{tabular}{lccccccr}
\hline & \multicolumn{3}{c}{ Left testis } & & \multicolumn{2}{c}{ Left epididymis } \\
\cline { 3 - 4 } \cline { 6 - 7 } Group & Weight $(\mathrm{g})$ & Johnsen score & $\begin{array}{c}\text { Seminiferous tubule } \\
\text { diameter }(\mu \mathrm{m})\end{array}$ & $\begin{array}{c}\text { Seminiferous epithelium } \\
\text { thickness }(\mu \mathrm{m})\end{array}$ & & Weight $(\mathrm{g})$ & $\begin{array}{c}\text { Sperm count } \\
\left(\mathrm{x} 10^{6} / \mathrm{g} \times \mathrm{ml}\right)\end{array}$ \\
\hline G1 & $1.42 \pm 0.07$ & $9.10 \pm 0.28$ & $276.21 \pm 4.66$ & $57.58 \pm 1.98$ & & $0.28 \pm 0.005$ & $1,552 \pm 184$ \\
G2 & $1.42 \pm 0.06$ & $6.44 \pm 0.38^{\mathrm{b}}$ & $223.10 \pm 9.45^{\mathrm{a}}$ & $48.35 \pm 0.99^{\mathrm{b}}$ & & $0.27 \pm 0.007$ & $980 \pm 85^{\mathrm{a}}$ \\
G3 & $1.46 \pm 0.06$ & $9.20 \pm 0.25$ & $293.25 \pm 7.45$ & $58.05 \pm 0.75$ & & $0.26 \pm 0.009$ & $1,356 \pm 176$ \\
G4 & $1.41 \pm 0.05$ & $6.67 \pm 0.41^{\mathrm{d}}$ & $230.62 \pm 10.12^{\mathrm{c}}$ & $47.87 \pm 1.42^{\mathrm{d}}$ & & $0.27 \pm 0.008$ & $930 \pm 92^{\mathrm{c}}$
\end{tabular}

${ }^{a} \mathrm{P}<0.05$ and ${ }^{\mathrm{b}} \mathrm{P}<0.01$ vs. $\mathrm{G} 1 ;{ }^{\mathrm{c}} \mathrm{P}<0.05$ and ${ }^{\mathrm{d}} \mathrm{P}<0.01$ vs. G3. G1 and $\mathrm{G} 3$ are 4 and 8 weeks post the sham operation, respectively; G2 and G4 are 4 and 8 weeks post experimental varicocele modelling, respectively. Data are presented as the mean \pm standard error of the mean. G1, group 1; G2, group 2; G3, group 3; G4, group 4.
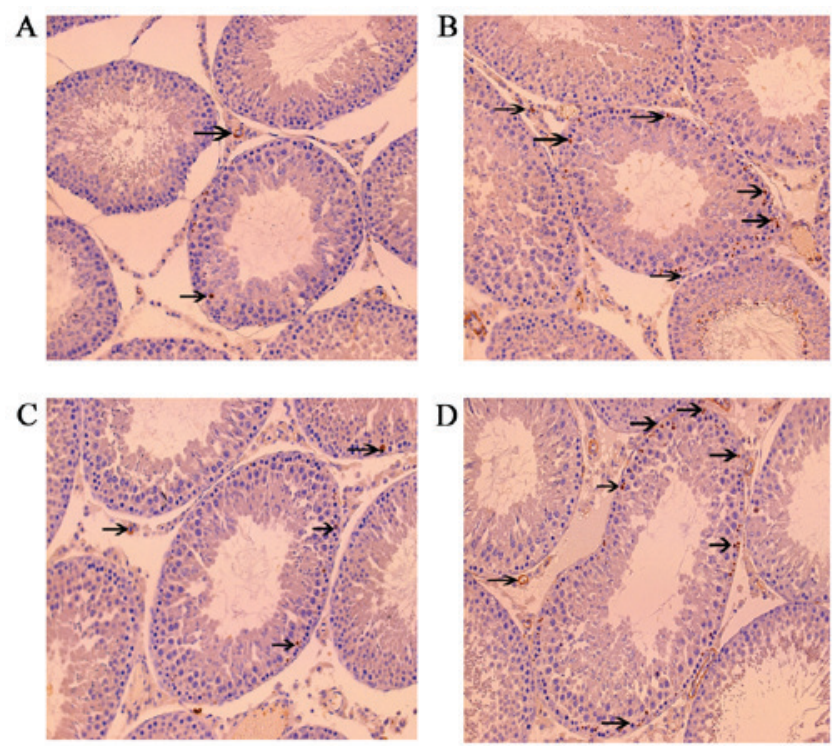

Figure 3. Immunohistochemistry staining of leptin in rats in the (A) G1, (B) G2, (C) G3 and (D) G4 groups. Magnification, x200. G1 and G3 were the control groups and G2 and G4 were the experimental varicoceles groups. Arrows indicate positive leptin stained cells. G1, group 1; G2, group 2; G3, group 3; G4, group 4.

respectively. There was no significant difference in serum levels of FSH, LH, and leptin (Table III).

Correlation analyses. The leptin level was inversely related to sperm count $(\mathrm{r}=-0.426, \mathrm{P}=0.043)$, thickness of the seminiferous epithelium $(r=-0.466, P=0.034)$, and the diameter of seminiferous tubules $(\mathrm{r}=-0.608, \mathrm{P}=0.004)$ (Fig. 9).

\section{Discussion}

Varicocele is an abnormal elongation, expansion, and tortuosity of the spermatic vein. Both animal and human studies have confirmed that varicocele can affect spermatogenesis (13). Our results showed that Johnsen scores in the left testis of the experimental varicocele groups (G2 and G4) were significantly lower, the seminiferous epithelium was thinner, the seminiferous tubule diameters were smaller, the sperm count was lower, and serum testosterone levels were decreased compared to those
A
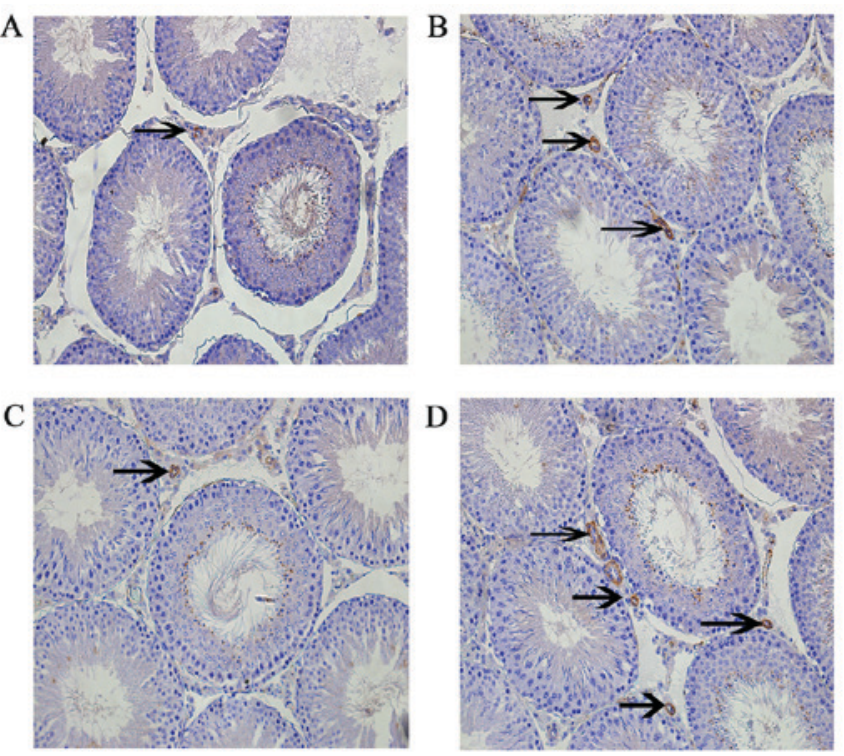

Figure 4. Immunohistochemistry staining of leptin receptor in rats in the (A) G1, (B) G2, (C) G3 and (D) G4 groups. Magnification, x200. G1 and G3 were the control groups and G2 and G4 were the experimental varicoceles groups. Arrows indicate positive leptin receptor stained cells. G1, group 1; G2, group 2; G3, group 3; G4, group 4.

in the control groups (G1 and G3). These results confirm that varicocele causes testicular dysfunction in rats.

Leptin plays an important role in both male and female reproductive systems. However, the precise relationship between leptin and male spermatogenesis has not been elucidated. Leptin receptors are found in hypothalamus, pituitary, testis, and sperm $(10,14)$. Our study found that leptin was expressed in seminiferous tubules and interstitium of testicular tissue, whereas leptin receptors were mainly expressed in the interstitium, consistent with prior research (15). Ishikawa (10) found overexpression of leptin and leptin receptors in testicular tissue of patients with varicocele. Chen et al (15) also found that the expression of leptin and its receptor in the testis of experimental varicocele rats increased, and was negatively correlated with testicular weight, Johnsen score, thickness of seminiferous epithelium, and diameter of the seminiferous tubules. Similarly, we found that varicocele increased the expression of leptin and leptin receptors in rat testis. 

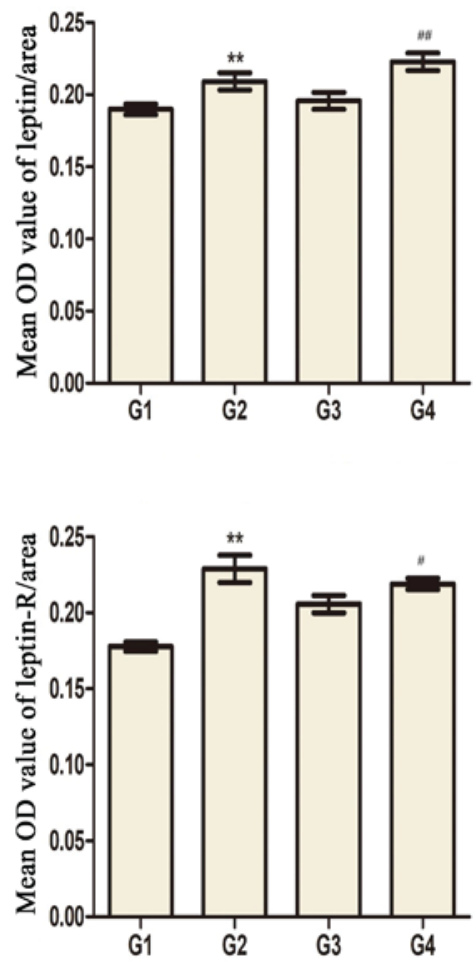

Figure 5. The OD values of anti-leptin and anti-leptin- $\mathrm{R}$ antibodies in the testes of different groups. ${ }^{* *} \mathrm{P}<0.01$ vs. the $\mathrm{G} 1$ group. ${ }^{\#} \mathrm{P}<0.05$ and ${ }^{\# \#} \mathrm{P}<0.01$ vs. the G3 group. G1 and G3 are 4 and 8 weeks post the sham operation, respectively; G2 and G4 are 4 and 8 weeks post experimental varicocele modelling, respectively. Leptin-R, leptin receptor; OD, optical density; G1, group 1; G2, group 2; G3, group 3; G4, group 4.
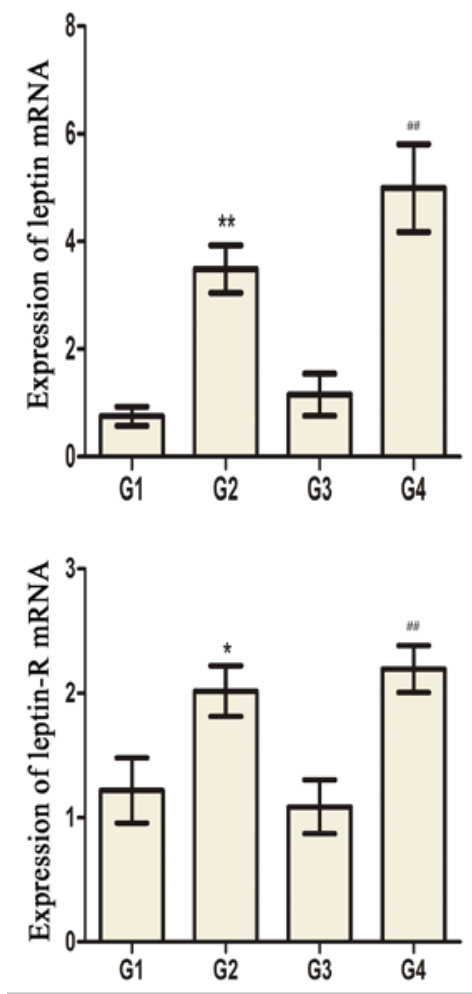

Figure 6. The mRNA expression of leptin and leptin-R in the testes of different groups. ${ }^{*} \mathrm{P}<0.05$ and ${ }^{* *} \mathrm{P}<0.01$ vs. the $\mathrm{G} 1$ group. ${ }^{\# \#} \mathrm{P}<0.01$ vs. the G3 group. G1 and G3 are 4 and 8 weeks post the sham operation, respectively; G2 and G4 are 4 and 8 weeks post experimental varicocele modelling, respectively. Leptin-R, leptin receptor; G1, group 1; G2, group 2; G3, group 3; G4, group 4.
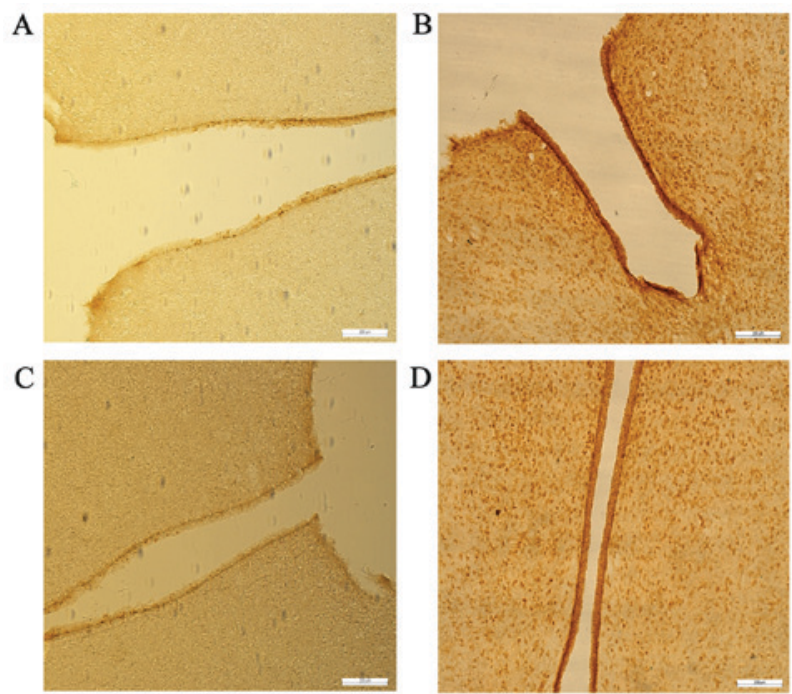

Figure 7. Immunohistochemistry staining of leptin receptor in the hypothalamus of rats in the (A) G1, (B) G2, (C) G3 and (D) G4 groups. Magnification, x100. G1, group 1; G2, group 2; G3, group 3; G4, group 4 .

Overexpression of leptin and leptin receptors is closely related to spermatogenesis dysfunction. We found that the expression of leptin was negatively correlated with sperm count, thickness of seminiferous epithelium, and diameter of the seminiferous tubules. However, it is still unknown what pathways leptin affects in the male reproductive system. Previous studies have shown that leptin plays a role in both central and peripheral tissues $(6,16)$. Leptin receptors are expressed on neurons secreting GnRH in the hypothalamus. Leptin is mainly involved in regulating $\mathrm{GnRH}$ secretion by this tissue by promoting the pulsatile secretion of GnRH through activating hypothalamic arcuate nucleus neurons (17). Our study found that leptin receptors were expressed mainly in Leydig cells whose major function is to secrete testosterone. This suggests that leptin and its receptor are likely to affect the reproductive system by regulating the secretion of testosterone. Tena-Sempere's study group found that leptin inhibited testosterone secretion by adult rat tissue in vitro and, in a subsequent study, found that leptin might inhibit testosterone secretion by down-regulating mRNA of some elements upstream of the steroidogenic pathway $(18,19)$.

Fombonne et al found that leptin could inhibit the division of immature Leydig cells (8). Our results showed that the expression of leptin and leptin receptors increased, and testosterone decreased significantly, in the experimental varicocele groups (G2 and G4). Overexpression of leptin and leptin receptors in testis tissue appears to be related to inhibition of testosterone secretion. There was a trend toward an increase in serum leptin in G2 and G4 compared with G1 and G3 rats, respectively, but neither reached significance. This result can be explained by the fact that serum leptin is regulated mainly by systemic metabolism and is related to the body mass index (20).

We found that expression of leptin receptors in the hypothalamus of rats in the experimental varicocele groups (G2 and G4) was increased. Furthermore, we also found that the mRNA levels of KiSS-1 GPR54, GnRH, LH, and FSH increased in the experimental varicocele groups. KiSS-1 is a coding gene for a tumor metastasis suppressor. The protein product is also called KiSS-1 and GPR54 is its receptor. KiSS-1/GPR54 is involved 
Table III. Serum hormonal evaluation.

\begin{tabular}{llccc}
\hline Group & T $(\mathrm{ng} / \mathrm{ml})$ & FSH $(\mathrm{mIU} / \mathrm{ml})$ & $\mathrm{LH}(\mathrm{mIU} / \mathrm{ml})$ & $\mathrm{Leptin}(\mathrm{pg} / \mathrm{ml})$ \\
\hline G1 & $0.95 \pm 0.39$ & $3.03 \pm 0.37$ & $4.71 \pm 0.33$ & $79.18 \pm 5.56$ \\
G2 & $0.20 \pm 0.08^{\mathrm{a}}$ & $3.32 \pm 0.63$ & $5.57 \pm 0.67$ & $113.39 \pm 18.18$ \\
G3 & $1.06 \pm 0.46$ & $3.18 \pm 0.52$ & $5.02 \pm 0.38$ & $88.42 \pm 7.86$ \\
G4 & $0.24 \pm 0.09^{\mathrm{b}}$ & $3.77 \pm 0.25$ & $5.84 \pm 0.38$ & $120.80 \pm 15.78$ \\
\hline
\end{tabular}

${ }^{\mathrm{a}} \mathrm{P}<0.01$ vs. G1; ${ }^{\mathrm{b}} \mathrm{P}<0.01$ vs. G3. G1 and G3 are 4 weeks and 8 weeks post the sham operation, respectively; G2 and G4 are 4 weeks and 8 weeks post experimental varicocele modelling, respectively. Data are presented as the mean \pm standard error of the mean. T, testosterone; FSH, follicle-stimulating hormone; LH, luteinizing hormone; G1, group 1; G2, group 2; G3, group 3; G4, group 4.
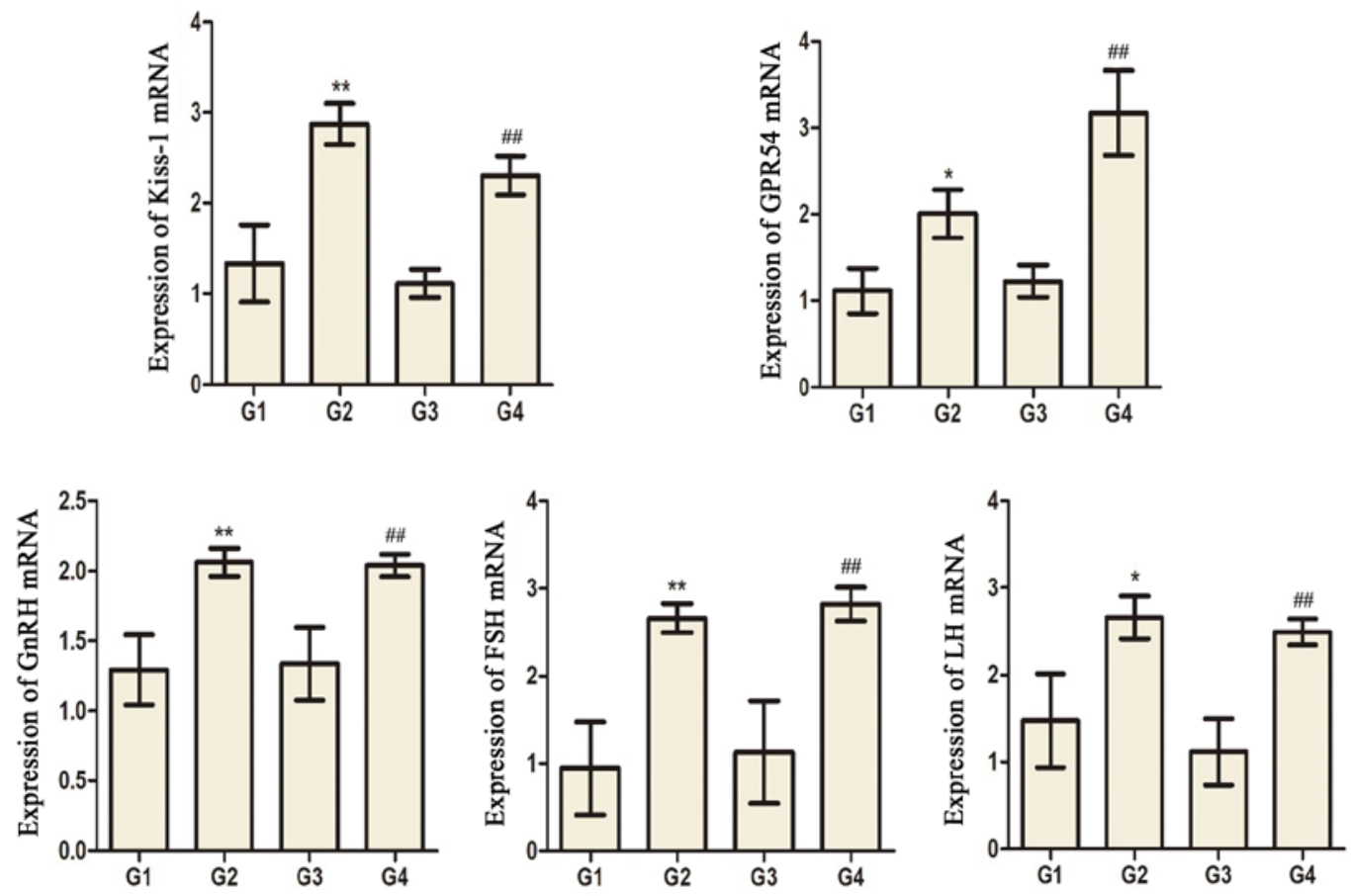

Figure 8. The mRNA expression of KiSS-1, GPR54, GnRH, FSH and LH in the hypothalamus tissues of different groups. "P<0.05 and ** P<0.01 vs. the G1 group. ${ }^{\# \mathrm{P}}<0.01$ vs. the G3 group. G1 and G3 are 4 and 8 weeks post the sham operation, respectively; G2 and G4 are 4 and 8 weeks post experimental varicocele modelling, respectively. KiSS-1, kisspeptin; GPR54, G-protein coupled receptor 54; GnRH, gonadotropin releasing hormone; FSH, follicle-stimulating hormone; LH, luteinizing hormone; G1, group 1; G2, group 2; G3, group 3; G4, group 4.
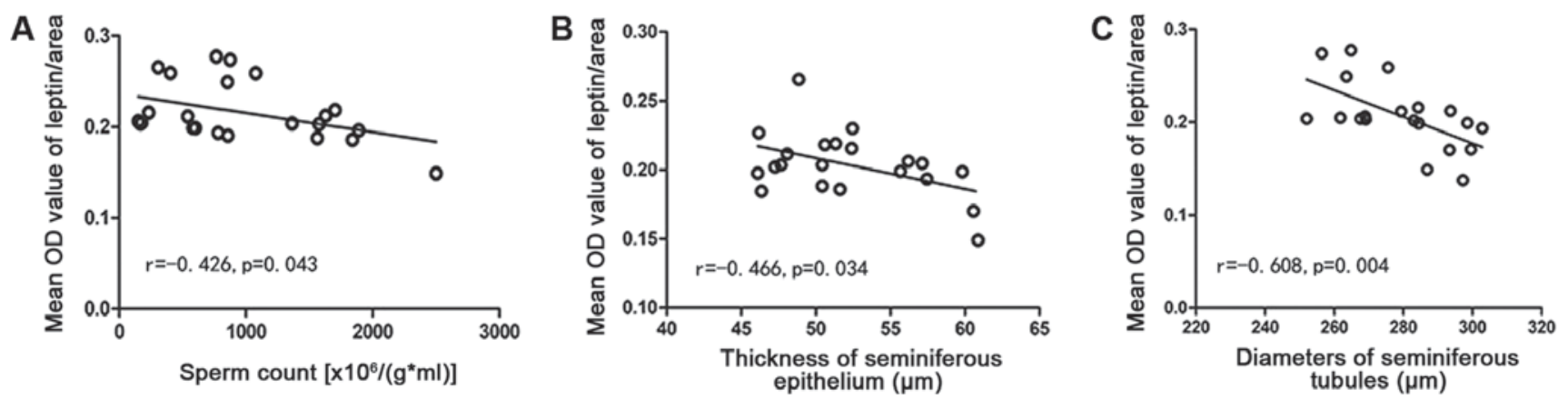

Figure 9. (A) Linear regression of OD and sperm count, (B) the thickness of seminiferous epithelium and (C) the diameters of seminiferous tubules. OD, optical density.

in regulating the hypothalamic-pituitary-gonadal axis which regulates levels of sex hormones by activating $\mathrm{GnRH}$ (21). The leptin receptor is present on KiSS-1 hypothalamic neurons, not on GnRH neurons (22), suggesting that peripheral leptin levels may regulate the hypothalamic-pituitary-gonadal axis by acting on the KiSS-1/GPR54 system. 
A recent study has shown that leptin not only promotes the expression of KiSS-1 and GPR54, but also expression of the leptin and androgen receptors. This suggests that leptin and androgen may have a positive synergistic effect on regulating the KiSS-1/GPR54 system (23). Therefore, we believe that the increased expression of leptin receptors in the hypothalamus caused by varicocele activated the KiSS-1/GPR54 system, resulting in upregulation of GnRH mRNA levels and then upregulation of LH and FSH mRNA levels. The KiSS-1 gene is a target for regulation by both leptin and testosterone (24). Therefore, the increased expression of $\mathrm{GnRH}$, $\mathrm{LH}$, and FSH can also be interpreted as negative feedback regulation of testosterone, or synergistic effects of leptin and testosterone.

The non-significant trend toward increased serum FSH and LH levels we observed in the experimental varicocele groups might be explained by the small sample size or short modeling time. Based on the results of our study, and the current understanding of leptin, we cannot fully define the role of leptin and leptin receptors in the pathogenesis of varicocele-induced testicular dysfunction. In part, this is because our results are only observational. Further studies, including both animal and in vitro cell experiments, are needed to clarify the mechanism.

Overexpression of leptin and the leptin receptor is closely related to spermatogenesis dysfunction. The results of our study indicate that varicocele can increase the expression of leptin and leptin receptors in rat testis, thus causing spermatogenesis dysfunction. Leptin and leptin receptors may have a significant role in the male reproductive system by regulating the KiSS-1/GPR54 system. Our study may help to further define the mechanism of how varicocele causes infertility and provide new ideas for treatment. However, understanding the exact role of leptin and leptin receptors in the pathogenesis of varicocele-induced testicular dysfunction requires further research and we are designing experiments to clarify the role of leptin in reproductive endocrinology and metabolism.

\section{Acknowledgments}

Not applicable.

\section{Funding}

This study was funded by the Research Grant for Health Science and Technology of Shanghai Municipal Commission of Health and family Planning (grant nos. 201440455 and ZHYY-ZXYJHZX-201602) and the Key Discipline Construction Project of Pudong Health and Family Planning Commission of Shanghai (grant no. PWZxk2017-21).

\section{Availability of data and materials}

All data generated or analyzed during this study are included in this published article.

\section{Authors' contributions}

JZ performed the research and wrote the paper. PPJ helped perform the research. MG designed the research and revised the paper. QTY and RJZ analyzed the data.

\section{Ethics approval and consent to participate}

The study was approved by the Ethical Committee of Shanghai Municipal Commission of Health and Family Planning (SWJW005).

\section{Consent for publication}

Not applicable.

\section{Competing interests}

The authors declare that they have no competing interests.

\section{References}

1. Lai YW, Hsueh TY, Hu HY, Chiu YC, Chen SS and Chiu AW: Varicocele is associated with varicose veins: A population-based case-control study. Int J Urol 22: 972-975, 2015.

2. Shiraishi K, Matsuyama H and Takihara H: Pathophysiology of varicocele in male infertility in the era of assisted reproductive technology. Int J Urol 19: 538-550, 2012.

3. Sáinz N, Barrenetxe J, Moreno-Aliaga MJ and Martínez JA: Leptin resistance and diet-induced obesity: Central and peripheral actions of leptin. Metabolism 64: 35-46, 2015.

4. Schulz LC and Widmaier EP: Leptin receptors. Endocrine Updates 83: 271-361, 2006.

5. Barash IA, Cheung CC, Weigle DS, Ren H, Kabigting EB, Kuijper JL, Clifton DK and Steiner RA: Leptin is a metabolic signal to the reproductive system. Endocrinology 137: 3144-3147, 1996.

6. Budak E, Fernández Sánchez M, Bellver J, Cerveró A, Simón C and Pellicer A: Interactions of the hormones leptin, ghrelin, adiponectin, resistin, and PYY3-36 with the reproductive system. Fertil Steril 85: 1563-1581, 2006.

7. Kawwass JF, Summer R and Kallen CB: Direct effects of leptin and adiponectin on peripheral reproductive tissues: A critical review. Mol Hum Reprod 21: 617-632, 2015.

8. Fombonne J, Charrier C, Goddard I, Moyse E and Krantic S: Leptin-mediated decrease of cyclin A2 and increase of cyclin D1 expression: Relevance for the control of prepubertal rat Leydig cell division and differentiation. Endocrinology 148: 2126-2137, 2007.

9. Grosfeld A, Andre J, Hauguel-De Mouzon S, Berra E, Pouyssegur J and Guerre-Millo M: Hypoxia-inducible factor 1 transactivates the human leptin gene promoter. J Biol Chem 277: 42953-42957, 2002.

10. Ishikawa T, Fujioka H, Ishimura T, Takenaka A and Fujisawa M: Expression of leptin and leptin receptor in the testis of fertile and infertile patients. Andrologia 39: 22-27, 2007.

11. Turner TT: The study of varicocele through the use of animal models. Hum Reprod Update 7: 78-84, 2001.

12. Johnsen SG: Testicular biopsy score count-a method for registration of spermatogenesis in human testes: Normal values and results in 335 hypogonadal males. Hormone 1: 2-25, 1970.

13. Agarwal A, Sharma R, Harlev A and Esteves SC: Effect of varicocele on semen characteristics according to the new 2010 World Health Organization criteria: A systematic review and meta-analysis. Asian J Androl 18: 163-170, 2016.

14. Smith MS, True C and Grove KL: The neuroendocrine basis of lactation-induced suppression of GnRH: Role of kisspeptin and leptin. Brain Res 1364: 139-152, 2010.

15. Chen B, Guo JH, Lu YN, Ying XL, Hu K, Xiang ZQ, Wang YX, Chen P and Huang YR: Leptin and varicocele-related spermatogenesis dysfunction: Animal experiment and clinical study. Int J Androl 32: 532-541, 2009

16. Donato J Jr, Cravo RM, Frazão R and Elias CF: Hypothalamic sites of leptin action linking metabolism and reproduction. Neuroendocrinology 93: 9-18, 2011.

17. Lebrethon MC, Vandersmissen E, Gérard A, Parent AS, Junien JL and Bourguignon JP: In vitro stimulation of the prepubertal rat gonadotropin-releasing hormone pulse generator by leptin and neuropeptide $\mathrm{Y}$ through distinct mechanisms. Endocrinology 141: 1464-1469, 2000. 
18. Tena-Sempere M, Pinilla L, González LC, Diéguez C, Casanueva FF and Aguilar E: Leptin inhibits testosterone secretion from adult rat testis in vitro. J Endocrinol 161: 211-218, 1999.

19. Tena-Sempere M, Manna PR, Zhang FP, Pinilla L, González LC, Diéguez C, Huhtaniemi I and Aguilar E: Molecular mechanisms of leptin action in adult rat testis: Potential targets for leptin-induced inhibition of steroidogenesis and pattern of leptin receptor messenger ribonucleic acid expression. J Endocrinol 170: 413-423, 2001.

20. Glander HJ, Lammert A, Paasch U, Glasow A and Kratzsch J: Leptin exists in tubuli seminiferi and in seminal plasma. Andrologia 34: 227-233, 2002.

21. Dungan HM, Clifton DK and Steiner RA: Minireview: Kisspeptin neurons as central processors in the regulation of gonadotropin-releasing hormone secretion. Endocrinology 147: 1154-1158, 2006.

22. Skorupskaite K, George JT and Anderson RA: The kisspeptin-GnRH pathway in human reproductive health and disease. Hum Reprod Update 20: 485-500, 2014
23. Morelli A, Marini M, Mancina R, Luconi M, Vignozzi L, Fibbi B, Filippi S, Pezzatini A, Forti G, Vannelli GB and Maggi M: Sex steroids and leptin regulate the 'first Kiss' (KiSS 1/G-protein-coupled receptor 54 system) in human gonadotropin-releasing-hormone-secreting neuroblasts. J Sex Med 5: 1097-1113, 2008.

24. Popa SM, Clifton DK and Steiner RA: The role of kisspeptins and GPR54 in the neuroendocrine regulation of reproduction. Annu Rev Physiol 70: 213-238, 2008.

This work is licensed under a Creative Commons Attribution-NonCommercial-NoDerivatives 4.0 International (CC BY-NC-ND 4.0) License. 